\title{
MULHERES EM DISCURSO: LINGUAGEM, POLÍTICA E VERDADE ${ }^{1}$
} Entrevista com Mónica Graciela Zoppi Fontana

Women in Discourse: language, politics and truth

Mónica Graciela Zoppi Fontana ${ }^{2}$

Universidade Estadual de Campinas - UNICAMP

\begin{abstract}
RESUMO: Nesta entrevista, a professora e linguista Mónica Zoppi Fontana apresenta, inicialmente, a formação do grupo de pesquisa que coordena, intitulado "Mulheres em Discurso", com a enumeração de alguns trabalhos desenvolvidos por seus membros. Eles visam, em comum, fomentar a reflexão sobre os processos de subjetivação da mulher, em nossa sociedade, por meio dos discursos e das práticas engendradas a partir deles. Em seguida, a pesquisadora trata da pósverdade, cenário no qual prevalecem afirmações de viés prioritariamente emotivo, do campo das crenças e das ideologias pessoais, diferentemente das afirmações que buscam se ancorar na maior aproximação dos fatos. Tal como observa, a pósverdade foi eleita a palavra do ano, em 2016, pelo Dicionário Oxford. Essa e outras razões de nosso contexto político exigem dos analistas do discurso uma análise desse fenômeno discursivo em sua relação com as fake news. Embora o emprego sistemático da mentira, em especial no campo político, não seja novo, o que impacta em nossa sociedade atual é o grau extraordinário de circulação e as formas de produção de evidências, em suas especificidades.
\end{abstract}

Palavras-chave: Análise do Discurso; Mulheres em Discurso; Política, Pósverdade; Fake news.

ABSTRACT: In this interview, the professor and linguist Mónica Zoppi Fontana initially presents the formation of the research group coordinates for her, entitled "Women in Discourse", with the enumeration of some works developed by her members. They aim, in common, to encourage reflection on the subjectivation processes of women in our society, through the discourses, and the practices generated from them. Then, the researcher deals with the post-truth, a scenario in

\footnotetext{
${ }^{1}$ Entrevista realizada no dia 14 de setembro de 2018, durante o V CIAD - Colóquio Internacional de Análise do Discurso: Discurso e (pós)verdade. Efeitos de real e sentidos da convicção. Na ocasião, a entrevistada proferiu a conferência "Pós-verdade e enunciação política: entre a mentira e o rumor". A equipe responsável pela produção, transcrição, retextualização e revisão desta entrevista foi composta por Andréia Martins Santana, Bianca Barbara Rapelli de Moraes, Bianca Cristina de Oliveira Fabiano, Bruno Ortega, Fernanda Rodrigues Neto, Gustavo D. C. Santos, Ingrid da Mata, Julia Santana, Karen Naomi Aisawa, Karina Rodrigues, Letícia de Santana Tizioto e Nadia Santos do Nascimento, discentes do curso de Bacharelado em Linguística da UFSCar, e por Luzmara Curcino, docente no Departamento de Letras e no Programa de Pós-graduação em Linguística da Universidade Federal de São Carlos (DL/PPGL/UFSCar), com o apoio de Leonardo Henrique Breda, Andrêi Krasnoschecoff, Manoel Sebastião Alves Filho, Daniel Perico Graciano, Lívia Beatriz Damaceno e Mónica Guerrero Garay. Esta entrevista, em sua versão audiovisual, está disponível em: $<\mathrm{http} / / / \mathrm{www}$.observatoriodaimprensa.com.br/pautas-contemporaneas/mulheres-em-discurso-linguagem-politicae-pos-verdade/>.

2 Doutora em Linguística, professora livre-docente junto à UNICAMP/IEL, atuando nas áreas de Semântica da Enunciação, Análise do Discurso e História das Ideias Linguísticas; é pesquisadora e líder do grupo de estudos "Mulheres em Discurso" - UNICAMP/CNPq. Autora, entre outros, dos livros: Cidadãos modernos. Discurso e representação, pela Editora da UNICAMP, em 2014; е O Português do Brasil como Língua Transnacional, pela RG - Editora, em 2009.
} 
which affirmations with a primarily emotional bias prevail, in the field of personal beliefs and ideologies, unlike the statements that seek to be anchored in the closest approximation of the facts. The post-truth was elected the word of the year in 2016 by the Oxford Dictionary. This and other reasons in our political context require discourse analysts to analyze this discursive phenomenon in their relationship with fake news. Although the systematic use of lies, especially in the political field, is not new, what impacts on our current society is the extraordinary degree of circulation and the forms of production of evidence, in their specificities.

Keywords: Discourse Analysis; Women in Speech; Politics; Post-truth; Fake news. 


\section{Mulheres em Discurso}

Entrevistadores: O grupo de pesquisa que a professora coordena intitula-se "Mulheres em discurso". De que tratam essas pesquisas?

Mónica Zoppi Fontana: O grupo de pesquisa "Mulheres em Discurso"3, fundado em 2013, desenvolveu, desde então, diversos trabalhos relativos à questão do gênero, e os primeiros resultados foram publicados sob a forma de livro, pela Editora Pontes, em dois volumes, intitulados Mulheres em discurso: gênero, linguagem e ideologia (2017a) e Mulheres em discurso: processos de identificação e práticas de resistência (2017b). A preocupação inicial desse projeto era pensar a configuração dos lugares de enunciação nos quais a voz de determinados sujeitos sociais estava historicamente silenciada ou em uma posição muito subalterna. Assim, decidimos unir essa preocupação teórica, a relação entre enunciação, discurso, ideologia e poder, às questões de gênero que vinham interessando as participantes do grupo.

Na primeira fase da pesquisa, Mulheres em Discurso - Lugares de enunciação $e$ processos de subjetivação, dedicamo-nos a pensar os diversos espaços que se estabeleceram historicamente como lugares de enunciação para a mulher, e isso abriu para uma diversidade bastante grande de campos diferentes para analisar esses lugares de enunciação, resultando em diversos trabalhos com essa temática, dentre os quais cito a pesquisa de Ana Josefina Ferrari (2014), intitulada Memória de mulheres agricultoras: uma leitura do trabalho rural de mulheres da comunidade quilombola de Batuva, que se dedicou à análise do silenciamento da enunciação de mulheres quilombolas do litoral paranaense, tanto por parte dos homens que as acompanhavam quanto pelas relações de poder existentes na comunidade quilombola, com a especificidade relativa a seu ostracismo; a tese de doutorado Vozes-mulheres negras ou feministas e antirracistas graças às Yabás, de Mariana Jafet Cestari (2015), que foi, inclusive, premiada pela ALED - Associação Latino-americana de Estudos do Discurso como melhor tese da América Latina; e o trabalho de Àgueda Aparecida da Cruz Borges (2013), intitulado Da aldeia para a cidade: processos de identificação/subjetivação do índio xavante em Barra do Garças-MT, alteridade irredutível?, que se dedicou a tratar da condição das mulheres indígenas, mais especificamente as mulheres xavantes, e como elas circulam na aldeia e na cidade de Barra do Garças. Com essas pesquisas pudemos observar esses lugares a partir dos

\footnotetext{
${ }^{3}$ Coordenado por Mónica Graciela Zoppi Fontana e Ana Josefina Ferrari, o grupo tem por objetivo apreender a relação entre o processo de constituição do sujeito político e social e as práticas discursivas que deslocam sentidos sobre as identificações de gênero, compreendido como uma construção discursiva, na história. Para mais informações, acessar o site oficial do grupo, disponível em: <https://www.facebook.com/MulherDis/>.
} 
quais uma voz dificilmente circula com legitimidade na história, de modo a tratarmos quais são os processos de subjetivação que se dão nessas condições de produção.

Ademais, conduzimos pesquisas também sobre a 'Marcha das Vadias', trabalho realizado por Tyara Veriato Chaves (2015); sobre a violência obstétrica, por Aline Azevedo (2017); sobre o turismo e a imagem da mulher, e do brasileiro em geral, nos guias de turismo franceses e brasileiros, de modo a mostrar como se dá a hiper sexualização do brasileiro, em especial, da mulher brasileira negra nesses guias, por Glória da Ressurreição Abreu França (2018); sobre a violência conjugal e a mulher em situação institucionalizada, nos abrigos, por Ana Paula Peron (2016). São, portanto, vários trabalhos que têm em comum analisar a maneira como os processos de subjetivação se constituem nessas condições de produção, nesses lugares onde a voz feminina dificilmente circula com legitimidade na história, abordando a questão da enunciação em relação ao discurso e à interdição ou deslegitimação de uma voz. Posteriormente, enquanto nos dedicávamos a essas pesquisas, deparamo-nos com a grande explosão midiática do debate sobre o lugar de fala, cuja circulação se deu, principalmente, no âmbito das redes sociais, instigado pela publicação da obra $O$ que é lugar de fala?, da filósofa Djamila Ribeiro (2017). Vínhamos nos preocupando com a questão da enunciação do ponto de vista teórico e fazendo pesquisas sobre determinados contextos específicos de fala quando essa publicação sobre o "lugar de fala" nos levou a aprofundar um pouco mais essa discussão.

Agora, na segunda fase, intitulada Mulheres, corpos, insurreições ${ }^{4}$, estamos interagindo no grupo com novos pesquisadores, todos também muito atuantes e comprometidos, cujas pesquisas enveredam para outras questões, nas quais a enunciação continua presente, mas agora relacionada a temas que envolvem o corpo, a representação do corpo e o modo como ele é significado, como a enunciação se ancora em uma representação da corporeidade e como isso se relaciona às questões de gênero. Assim, em nosso grupo temos desenvolvido pesquisas dedicadas ao feminismo islâmico (Gabriela Hollas e Fernanda Pereira), transfeminismo (Beatriz Bagagli), feminismo neoliberal e mulheres no mundo corporativo (Raquel Noronha), literatura e escrita face à violência de Estado (Tyara Chaves), legitimação das trabalhadoras sexuais (Maria Fernanda Moreira), empoderamento (Laís Medeiros), mulheres cafeicultoras e o agronegócios, entre outros temas, abarcando, creio eu, as diversas facetas e dimensões da questão do feminino e do gênero e, de modo mais amplo e específico, em relação às questões da mulher na sociedade brasileira, amplamente

\footnotetext{
${ }^{4}$ Essa nova fase da pesquisa está relacionada com o meu projeto CNPq-Bolsa PQ processo 307842/2017-7, intitulado Mulheres, corpo e insurreição - Greve de mulheres, novos sentidos para uma velha prática.
} 
Mónica Graciela Zoppi Fontana (entrevista). Mulheres em discurso: linguagem, política e verdade.

representadas pelos trabalhos do grupo. Recentemente criamos o podcast Mulheres em Poehmas, uma iniciativa surgida em tempos de pandemia, que propõe a cada semana a leitura de um poema de autoria feminina, declamado por um integrante do grupo ou convidado ${ }^{5}$.

Tendo em vista essas pesquisas e os seus resultados, estou muito feliz com o funcionamento do grupo e com a relevância dos debates realizados até o presente momento, bem como com o estabelecimento de relações com outros grupos de pesquisa, tanto no Brasil ${ }^{6}$ quanto na Argentina ${ }^{7}$ e na França ${ }^{8}$, que também se dedicam ao tema.

\section{Linguagem, política e (pós)verdade}

Entrevistadores: Sua conferência no V CIAD abordou um tema atual e que tem sido com relativa frequência tratado na mídia em relação à política, a saber o tema da 'pós-verdade'. De que ponto de vista a pesquisadora tem tratado esse tema?

Mónica Zoppi Fontana: Ao longo de meu percurso de trabalho, preocupei-me com a relação entre língua(gem) e política. A minha tese de doutorado, por exemplo, é dedicada ao discurso político argentino sobre a modernização do Estado na década de 80. Mesmo trabalhando temas mais amplos como questões ligadas ao espaço urbano, ao gênero e às políticas linguísticas, sempre acabo discorrendo sobre o funcionamento do político na sociedade, buscando entender o modo como a linguagem participa disso e qual é o seu papel nesse processo.

Recentemente, a partir de convites que tenho recebido para participar de eventos, a

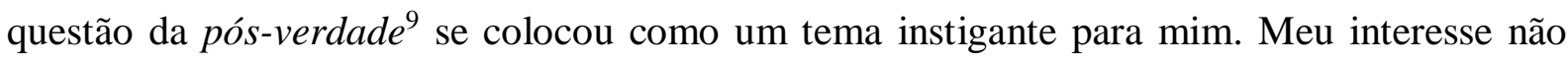
recai tanto sobre a conceituação da verdade em si, sobre o modo como ela poderia ser conceituada do ponto de vista filosófico ou em sua dimensão referencial na sua relação com o mundo e o estado de coisas aos quais corresponderia. Eu passei a pensar a questão da pós-

\footnotetext{
${ }^{5}$ Cf. <https://anchor.fm/mulheresempoehmas>.

${ }^{6}$ Notadamente com colegas da UFMA, UFPE, UFAL, UFF, UNEMAT, CEFET-BH, UFSCAR, UFPR-Litoral, UNIOESTE, UFSC, UFRGS, entre outras instituições do país.

${ }^{7}$ Com as equipes de pesquisa lideradas por Julia Zullo e Mara Glozsman na Universidad de Buenos Aires, e Pedro Karczmarczyk na Universidad Nacional de La Plata.

${ }^{8}$ Como grupo de pesquisa liderado pela professora Marie-Anne Paveau, junto ao Laboratório Plèiade da Université de Paris Nord - Paris 13 e com a equipe do professor Thierry Guilbert, da Université de Picardie Jules Verne.

9 "De acordo com a definição proposta pelo dicionário Oxford, a palavra 'pós-verdade' se refere a 'circunstâncias em que os fatos objetivos têm menos influência na formação da opinião pública do que os apelos à emoção e à opinião pessoal” (ZOPPI FONTANA, 2018, p. 141, grifos originais).
} 
verdade em termos enunciativos, em outras palavras, levando em consideração que dispositivos de enunciação e que condições de produção permitem produzir como 'efeito' aquilo que se convencionou chamar, na sociedade atual, de pós-verdade, de uma enunciação da pós-verdade. Para trabalhar essa questão utilizei-me, como em todos os meus trabalhos, de recortes para a constituição de um corpus de análise, sendo esses recortes, por exemplo, textos nos quais se atesta o uso das palavras pós-verdade ou fake news; com base nesse corpus propus uma análise da circulação desses termos.

Os primeiros trabalhos que desenvolvi sobre o tema da pós-verdade foram apresentados em um evento na França, na Universidade de Reims Champagne-Ardenne, e posteriormente, por solicitação da Universidade do Estado de Mato Grosso (UNEMAT), trabalhei, em um $\operatorname{artigo~}^{10}$, o discurso lexicográfico acerca desse conceito, estudando como os verbetes das Wikipedias francesa, inglesa e brasileira, bem como o Dicionário Oxford e outros dicionários, tentavam estabelecer e estabilizar um modo de compreensão do conceito de pósverdade.

No meu trabalho, considero a pós-verdade como uma forma histórica de enunciação, como um dispositivo específico, que produz e faz circular enunciados segundo certas condições de produção do discurso político, como as atuais, que integram, como um dos seus elementos constitutivos, o cinismo, nos termos em que foi definido por Sloterdijk ${ }^{11}$ e Baldini $^{12}$, isto é, como uma forma de subjetivação contemporânea.

Mais recentemente, relacionei o tema da pós-verdade à questão das fake news, e tenho tentado estabelecer entre elas uma diferença de funcionamento no âmbito da enunciação. No corpus que tenho reunido e analisado, constatei que a pós-verdade sempre aparece relacionada à enunciação de uma figura identificável, geralmente a um ator político destacado. A enunciação se dá, portanto, a partir de uma relação com o nome próprio, com uma autorização do dizer a partir de uma instância social já legitimada. É essa relação com um locutor já legitimado e cujo dizer está autorizado institucionalmente que aproxima a enunciação da pós-verdade ao funcionamento da mentira na política, como estudada por JeanJacques Courtine, por exemplo ${ }^{13}$. Já em relação às fake news, o funcionamento é diferente, pois se tem um discurso que se mostra como um dizer sobre a realidade, mas que não corresponde a ela, nem se sobrepõe a ela.

\footnotetext{
${ }^{10}$ Cf. Zoppi Fontana (2018).

${ }^{11}$ Cf. Sloterdijk (1983).

12 Para Baldini e Di Nizo (2015, p. 140), o cinismo é um tipo de ironia "considerado a partir de um lugar de enunciação fora do poder, tal como na figura clássica de Diógenes. O cínico é aquele que, pondo em risco seu corpo a partir de sua coragem de enunciar, desnuda o discurso do poder através da ironia".

${ }^{13}$ Cf. Courtine (2006).
} 
Assim, enquanto dispositivo enunciativo, enunciados do âmbito da pós-verdade são diferentes daqueles que nomeamos como fake news, porque esses últimos funcionam sob a forma de boatos que não correspondem aos fatos, circulam anonimamente na sociedade, principalmente nas redes sociais, de forma 'clandestina', de modo que não têm relação nem com um lugar social já legitimado, que autorizaria um dizer, nem com um nome próprio reconhecível, um locutor que possa ser associado a uma figura política. Elas circulam, se multiplicam, se repetem e se espalham de forma anônima, espontânea e não identificável nas redes sociais, produzindo, assim, sentido.

\section{Textos, leitura e efeitos de (pós)verdade}

Entrevistadores: Há mudanças na leitura dos textos sobre a política, que circulam nas mídias tradicionais mas também por meio das redes sociais, que se poderia observar em tempos de pós-verdade e fake news?

Mónica Zoppi Fontana: Essa pergunta a respeito do modo como os debates atuais sobre a pós-verdade envolvem uma reflexão em relação ao efeito-leitor ${ }^{14}$ é muito interessante. Eu considero que designar como pós-verdade uma determinada prática enunciativa é já um modo de leitura dessa prática enunciativa; é justamente esse aspecto o que me motiva a trabalhar com a circulação dessas designações, dessas formas de nomeação de diferentes práticas enunciativas. Ao se considerar a enunciação de um sujeito, ou um determinado modo de dizer como uma pós-verdade, atribuem-se determinadas características a essa enunciação e, com isso, produz-se um certo sentido.

Então, pode-se dizer que a questão dos sentidos atribuídos a palavra pós-verdade circula em diferentes campos discursivos e tem a ver com um modo de dizer ou prática enunciativa, como por exemplo nos debates surgidos em torno dessa questão na mídia e também na Academia. Há alguns aspectos que já aparecem sinalizados nessa discussão e que apontam, do meu ponto de vista, ao funcionamento da enunciação. Por exemplo, é preciso considerar que a pós-verdade diz mais a respeito do sujeito que enuncia que do objeto sobre o qual discorre; não se trata somente do fato de um sujeito enunciar algo que não é verdadeiro, mas de fazê-lo de um modo emocional, e, inclusive, de forma deliberadamente mentirosa.

\footnotetext{
${ }^{14}$ Cf. Orlandi (2004).
} 
Assim, o sujeito sustenta e afirma aquilo que de alguma maneira ele sabe que não corresponde ao estado de coisas no mundo ao qual se refere.

Quando se designa uma prática enunciativa como pós-verdade explicita-se, em termos de produção de sentido, tudo isso: um locutor legitimado, autorizado para dizer, que enuncia como sendo verdadeiro algo que ele considera falso. É nesse sentido que nomear como pósverdade uma prática enunciativa é já projetar um gesto de leitura, é ler de alguma maneira a circulação da fala pública, e projetar uma interpretação sobre essa enunciação e quem a realiza.

Eu às vezes brinco, quando falo sobre essa temática, que nós, no cotidiano de nossas vidas, podemos mentir - e, de fato, mentimos muitas vezes -, mas ninguém diria que nós falamos ou produzimos pós-verdades, porque falar em pós-verdade implica considerar a circulação social de uma fala pública, de um ator no campo do político ou no campo do jornalístico. Não se trata, portanto, de um dizer acontecido no espaço privado, no espaço da intimidade e das interlocuções corriqueiras. Uma mentira no cotidiano é uma mentira, um mentiroso é um mentiroso e um fofoqueiro é um fofoqueiro, mas quando se está falando da circulação social de falas públicas, de locutores legitimados, a questão toma outra dimensão e ali é que se utiliza nos debates públicos as noções de pós-verdade e de fake news. Portanto, uma fofoca no âmbito público sustentada pela repetição de circulação nas redes sociais é fake news, é um boato específico que incide na circulação política do sentido, produzindo impacto na construção de evidência. A pós-verdade incide na fala pública de atores políticos, produzindo também impactos nos efeitos de subjetivação e identificação, principalmente dos eleitores. Por isso, essa discussão sempre toca em uma relação quase necessária entre a mídia e a política. Quando se fala em pós-verdade, se fala dessa relação: do jornalismo, do jornalismo político, da enunciação política, da política institucionalizada e das relações espúrias que às vezes se estabelece entre esses dois campos.

\section{Referências}

BALDINI, Lauro José Siqueira; DI NIZO, Patrícia Leal. O Cinismo como prática ideológica. Estudos da Língua(gem), [S.1.], v. 13, n. 2, p. 131-158, dez. 2015. Disponível em: <http://periodicos2.uesb.br/index.php/estudosdalinguagem/article/view/1305>. Acesso em: 19 nov. 2019. DOI: https://doi.org/10.22481/el.v13i2.1305.

BORGES, Águeda Aparecida da Cruz. Da aldeia para a cidade: processos de identificação/subjetivação do índio xavante em Barra do Garças-MT, alteridade irredutível? 2013. 215 f. Tese (Doutorado em Linguística) - Instituto de Estudos da Linguagem, 
Universidade Estadual de Campinas, Campinas, SP, 2013. Disponível em: <http://repositorio.unicamp.br/jspui/handle/REPOSIP/271078>. Acesso em: 08 nov. 2019.

CESTARI, Mariana Jafet. Vozes-mulheres negras ou feministas e antirracistas graças às Yabás. 2015. 264 f. Tese (Doutorado em Linguística) - Instituto de Estudos da Linguagem, Universidade Estadual de Campinas, Campinas, SP, 2015. Disponível em: <http://repositorio.unicamp.br/jspui/handle/REPOSIP/271056>. Acesso em: 08 nov. 2019.

CHAVES, Tyara Veriato. Da Marcha das Vadias às vadias da marcha: discursos sobre as mulheres e o espaço. 2015. 145 f. Dissertação (Mestrado em Linguística) - Instituto de Estudos da Linguagem, Universidade Estadual de Campinas, Campinas, SP, 2015. Disponível em: <http://repositorio.unicamp.br/jspui/handle/REPOSIP/271053>. Acesso em: 08 nov. 2019.

COURTINE, Jean-Jacques; SWIFT, Jonathan. A arte da mentira política. Precedido do texto "O mentir verdadeiro" de Jean-Jacques Courtine. Tradução Mónica Zoppi Fontana e Roberto Leiser Baronas. Campinas, SP: Pontes, 2006.

FERRARI, Ana Josefina. Memória de mulheres agricultoras: uma leitura do trabalho rural de mulheres da comunidade quilombola de Batuva. In: VIII Congresso brasileiro de pesquisadores/as negros/as - COPENE 2014, 2014, Belém. Anais do VIII Congresso brasileiro de pesquisadores/as negros/as, 2014. p. 1-14.

FRANÇA, Glória da Ressurreição Abreu. Gênero, raça e colonização: a brasilidade no olhar do discurso turístico no Brasil e na França. 2018. 363 f. Tese (Doutorado em Linguística) Universidade Estadual de Campinas, Instituto de Estudos da Linguagem e Université Paris 13 Sorbonne Paris Cité, Campinas, SP. Disponível em: <http://repositorio.unicamp.br/jspui/handle/REPOSIP/331559>. Acesso em: 08 nov. 2019.

ORLANDI, Eni Puccinelli. Interpretação. Autoria, leitura e efeitos do trabalho simbólico. Campinas: Pontes, 2004.

PERON, Ana Paula. Ser mulher, sentir a violência, enunciar os sentimentos: um olhar discursivo sobre a humilhação na condição de violência conjugal. 2016. 140 f. Tese (Doutorado em Linguística) - Instituto de Estudos da Linguagem, Universidade Estadual de Campinas, Campinas, 2016. Disponível em: <http://repositorio.unicamp.br/jspui/handle/REPOSIP/321636>. Acesso em 08 nov. 2019.

RIBEIRO, Djamila. O que é lugar de fala? Belo Horizonte: Letramento, 2017.

SLOTERDIJK, Peter. Crítica da razão cínica. São Paulo: Estação Liberdade, 2012. (Edição original: 1983)

ZOPPI FONTANA, Mónica Graciela. Pós-verdade: léxico, enunciação e política. In: OLIVEIRA, Rosimar R. Rodrigues; OLIVEIRA, Sheila Elias de; RODRIGUES, Marlon Leal; KARIM, Taisir Mahmudo. (Orgs.). Linguagem e significação: práticas sociais. Campinas, SP: Pontes, 2018, p. 113-166. Disponível em: $<$ https://www.academia.edu/38590891/POS-VERDADE-

_LEXICO_ENUNCIACAO_E_POLITICA-compactado.pdf>. Acesso em: 08 nov. 2019. 
ZOPPI FONTANA, Mónica Graciela; FERRARI, Ana Josefina (Orgs.). Mulheres em discurso: Gênero, Linguagem e Ideologia. Campinas, SP: Pontes, 2017a.

ZOPPI FONTANA, Mónica Graciela; FERRARI, Ana Josefina (Orgs.). Mulheres em discurso: Processos de identificação e práticas de resistência. 1. ed. Campinas, SP: Pontes, $2017 \mathrm{~b}$.

Recebido em: 12 de fevereiro de 2020.

Aceito em: 17 de abril de 2020. 